\title{
Effective engineering solutions for drainage systems in peat soils
}

\author{
Andrey Nikitin ${ }^{1, *}$, and Olga Zaborskaya ${ }^{1}$ \\ ${ }^{1}$ Northern Federal University named after M.V. Lomonosov (NArFU), 17 Severnaya Dvina Emb., \\ Arkhangelsk, 163002, Russia
}

\begin{abstract}
The article describes the feasibility of using a stone-free drainage system for water depression in peaty soils. The purpose of the research is to develop economical and technological engineering solutions for drainage in peat soils. A specimen of a stone-free drainage system, including a perforated corrugated pipe $150 \mathrm{~mm}$ in diameter and expanded polysterene pellets as aggregate, was studied in laboratory conditions. Geotextile filters were wrapped around both the aggregate and the drain pipe. The drainage system specimen was subjected to a load equivalent to that applied by 1 to $4 \mathrm{~m}$ of backfilling sand. The study established high deformability of the drain pipe and the pelletized expanded polysterene aggregate, as well as a considerable decrease in the aggregate water permeability. The burial depth of a typical stone-free drainage system shall be limited by $2.5 \mathrm{~m}$. The article shows that the presence of clogging particles in drain water may lead to a considerable decrease in permeability of geotextile filters on drain pipes. The proposed design of stone-free drainage system in peaty soils ensures lower material consumption, cost, and workload. To reduce deformations of stone-free drainage system structural components, pipes and aggregate of non-yielding (stiff) materials shall be used.
\end{abstract}

\section{Introduction}

Construction on peaty soils is often associated with water depression activities. Where peat thickness is small, drains are placed on mineral bottom. With a considerable peat thickness, drains shall be installed on pile foundations. A typical drainage system design is shown in Figure 1, and name of elements in Figure 2. Prism-shaped piles of $300 \times 300 \mathrm{~mm}$ crosssection are driven into the mineral soil to the depth of at least $2 \mathrm{~m}$. Reinforced concrete caps can be pre-cast or cast-in-place. Drains pipes are perforated asbestos-cement or plastic pipes up to $300 \mathrm{~mm}$ in diameter. Crushed stone is used as pipe cover (drain aggregate). The recent practice is to have pipes wrapped in geotextile fabric. It has high water permeability, chemical stability, and soil tightness, which reduces silting of drain pipes [1-5]. Wooden panels are used to ensure the stability of drain aggregate as peat settles down in service.

\footnotetext{
* Corresponding author: nikitinavsafu@yandex.ru
} 


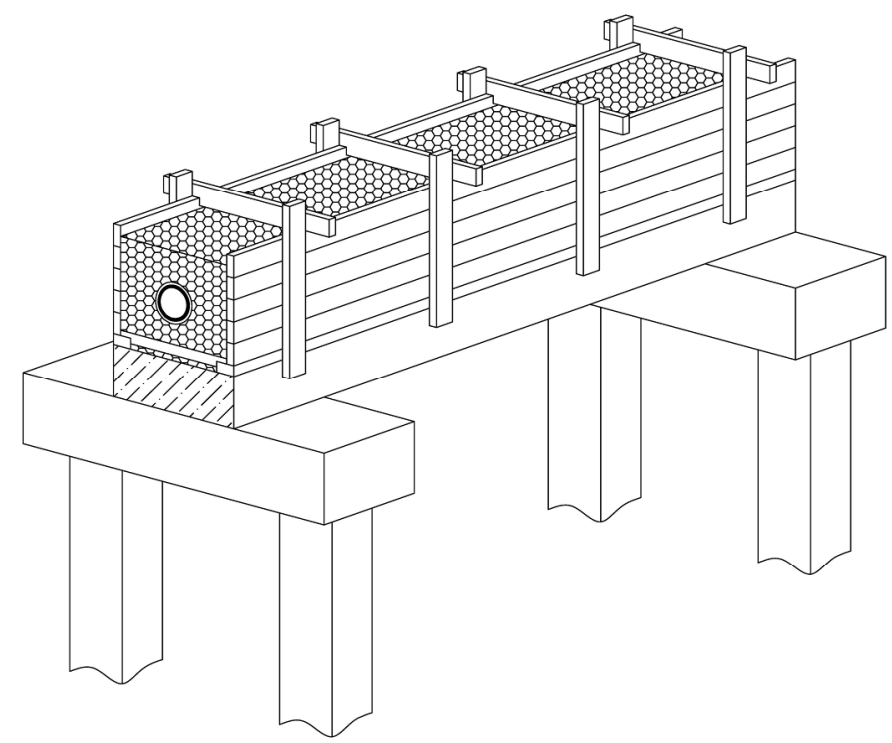

Fig. 1. Drain arrangement on reinforced concrete piles

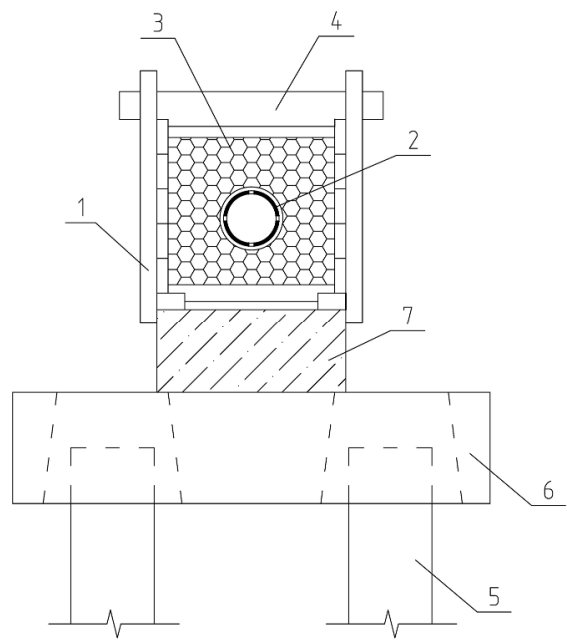

Fig. 2. Elements of a typical design of drain on pile foundations. 1 - wooden panel, 2 - drain pipe, 3 aggregate, 4 - tie member, 5 - reinforced concrete pile, 6 - reinforced concrete cap, 7 - reinforced concrete beams

The typical drain design has certain disadvantages: a considerable weight, high material consumption and construction costs. Besides, operation of typical drainage systems has shown that their water intake capacity will decrease drastically with time. In some cases such drains stop working altogether requiring re-installation. Disturbance of the drain's normal operation may be caused by decreasing water permeability of the drain aggregate and geotextile filters due to mineral and organic particles carried over by groundwater [6$10]$.

At present, a drain design excluding crushed stone cover has come into use. It allows reducing labour input and improving cost efficiency (Figure 3). Such a drainage system includes a corrugated tubular drain. The aggregate is made of spherical or prism-shaped expanded polysterene pellets $20-50 \mathrm{~mm}$ in size, which are placed around the pipe. Using 
polysterene foam for aggregate helps to reduce the weight of the structure considerably. Geotextile filters are installed both over the aggregate's outer envelope and around the drain pipes. This design makes the drain system easier to install and maintain.

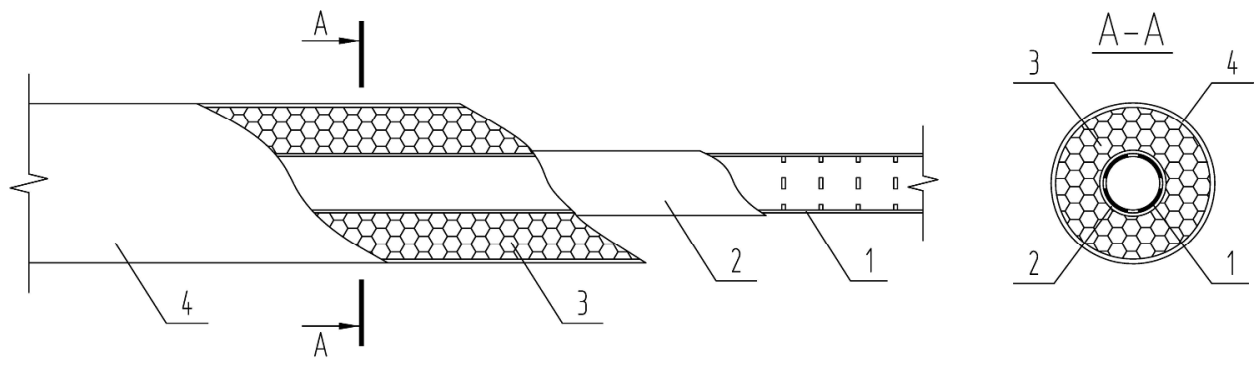

Fig. 3. Design of drainage system without crushed stone. 1 - perforated corrugated pipe; 2 geotextile (density 100); 3 - expanded polysterene pellets, 4 - geotextile (density 250 )

\section{Laboratory experiments}

A stone-free drainage system was tested in the laboratory to evaluate its applicability in peaty soils. A specimen of stone-free drain was tested in a laboratory box measuring $70 \times 65 \times 30 \mathrm{~cm}$ with transparent walls (Figure 4).

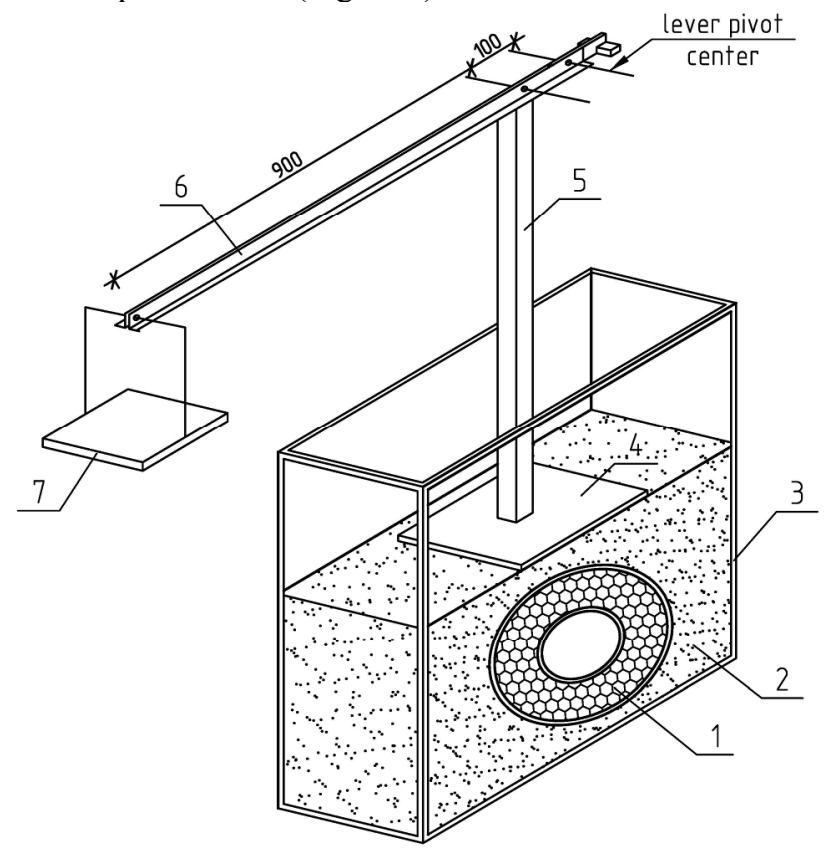

Fig. 4. Laboratory set-up for stone-free drain testing. 1 - stone-free drainage system; 2 - sand filling; 3 box; 4 - stamp; 5 - post; 6 - lever; 7 - loading platform

A $30 \mathrm{~cm}$ long fragment of stone-free drain was placed into the box. The fragment was composed of a perforated (slotted) corrugated polyvinyl chloride pipe with the outside diameter of $160 \mathrm{~mm}$, which was wrapped in geotextile with the density of $100 \mathrm{~g} / \mathrm{m}^{2}$. The pipe inside diameter was $138 \mathrm{~mm}$, and the pipe wall thickness was $1 \mathrm{~mm}$. Expanded polysterene pellets were used as aggregate all around the pipe with the layer thickness of $100 \mathrm{~mm}$. Geotextile with the density of $250 \mathrm{~g} / \mathrm{m}^{2}$ was placed over the aggregate's outer 
envelope. The box was filled with coarse sand. A load equivalent to 1 to $4 \mathrm{~m}$ of sand backfilling was applied to the drain via a stamp with the footprint of $0.25 \times 0.28 \mathrm{~m}$. A lever was used to create the required pressure and apply the load to the drain specimen via the stamp. Vertical and horizontal deformations of the drain pipe were recorded in the course of the experiment. The results of drain pipe testing are summarized in Table 1.

Table 1. Deformation of drain pipe under load

\begin{tabular}{|c|c|c|c|}
\hline $\begin{array}{c}\text { Load, } \mathrm{kPa}, \\
\text { equivalent } \\
\text { to sand layer } \\
\text { thickness, } \mathrm{m}\end{array}$ & \multicolumn{2}{|c|}{$\begin{array}{c}\text { Pipe cross-section dimension after } \\
\text { load application, mm }\end{array}$} & $\begin{array}{c}\text { Vertical } \\
\text { deformation } \\
\text { of drain } \\
\text { pipe, } \mathrm{mm}\end{array}$ \\
\cline { 2 - 3 } & $\begin{array}{c}\text { vertical, } \\
\mathrm{d}_{1}\end{array}$ & $\begin{array}{c}\text { horizontal, } \\
\mathrm{d}_{2}\end{array}$ & 3 \\
\hline $18(1)$ & 135 & 141 & 10 \\
\hline $36(2)$ & 128 & 145 & 38 \\
\hline $54(3)$ & 100 & 167 & 128 \\
\hline $72(4)$ & 10 & 188 & \\
\hline
\end{tabular}

As we can see, a corrugated PVC drain pipe is highly deformable, and it can be used at the burial depth of up to $2.5 \mathrm{~m}$. For a greater burial depth, stiff pipes of unplasticized polyvinyl chloride or polypropylene can be considered. Besides, a considerable settlement of expanded polysterene was also detected.

The aggregate material shall ensure sufficient water permeability during the drain service life. Changes in water permeability and compressibility of expanded polysterene pellets under load were measured in a filtration tube $110 \mathrm{~mm}$ in diameter. A pressure of 18 $72 \mathrm{kPa}$ corresponding to the soil backfilling layer thickness of 1 to $4 \mathrm{~m}$ was applied to a expanded polysterene specimen $280 \mathrm{~mm}$ in height via a perforated stamp $100 \mathrm{~mm}$ in diameter. Figure 5 demonstrates the design of the filtration tube.

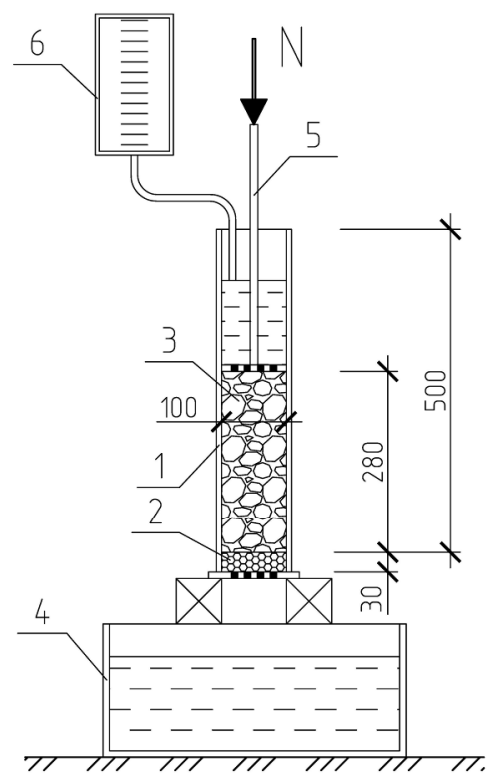

Fig. 5. Set-up for compression and filtration testing of expanded polysterene. 1 - filtration tube; 2 gravel; 3 - expanded polysterene pellets; 4 - water collection tray; 5 - loading device; 6 - graduated cylinder

In addition, compressibility and water permeability studies were also conducted for extruded polystyrene foam in the form of spherical pellets $40 \mathrm{~mm}$ in diameter. Extruded 
polystyrene foam has higher stiffness and lower compressibility. During the experiment, deformation and water permeability of extruded polystyrene foam pellets were determined with reference to the load applied. Water level in the filtration tube was maintained the same during the experiment. For water permeability measurement, the initial head gradient of 1.5 was adopted. In view of considerable compressibility, the head gradient was increased to 11 for expanded polysterene, and to 2.4 for extruded polystyrene foam.

Table 2 presents the results of compression-filtration testing of expanded polystyrene and extruded polystyrene foam, which can be used as drain aggregates. The filtration coefficient of aggregate materials was determined by formula (1):

$$
k_{f}=\frac{Q}{A t I}
$$

$Q$ - is the volume of water passed through the specimen;

$A$ - is the pipe cross-sectional area;

$t$ - is the duration of filtration;

$I$ - is the hydraulic head gradient.

Table 2. Change of water permeability of drain aggregate materials under pressure

\begin{tabular}{|c|c|c|c|}
\hline $\begin{array}{c}\text { Pressure } \\
\text { on specimen, } \\
\mathrm{kPa}\end{array}$ & $\begin{array}{c}\text { Relative deformation, } \\
\text { unit fractions }\end{array}$ & Head gradient & $\begin{array}{c}\text { Filtration coefficient, } \\
\mathrm{m} / \mathrm{hr}\end{array}$ \\
\hline \multicolumn{4}{|c|}{ Expanded polystyrene pellets } \\
\hline 0 & 0 & 1.5 & 131.5 \\
\hline 18 & 0.40 & 2.44 & 33.4 \\
\hline 36 & 0.63 & 3.93 & 4.8 \\
\hline 45 & 0.72 & 5.32 & 2.0 \\
\hline 54 & 0.79 & 6.95 & 0.70 \\
\hline 63 & 0.82 & 8.08 & 0.59 \\
\hline 72 & 0.87 & 11.05 & 0.40 \\
\hline \multicolumn{5}{|c|}{ Extruded polystyrene foam pellets } \\
\hline 0 & 0 & 1.50 & 140.5 \\
\hline 18 & 0.11 & 1.65 & 117.2 \\
\hline 36 & 0.20 & 1.83 & 80.3 \\
\hline 45 & 0.26 & 1.98 & 74.2 \\
\hline 54 & 0.30 & 2.09 & 65.8 \\
\hline 63 & 0.35 & 2.26 & 54.9 \\
\hline 72 & 0.39 & 2.40 & \\
\hline
\end{tabular}

Filtration tube surveys have shown that the filtration coefficient of expanded polystyrene aggregate drops drastically with the growing load. The reason for this is high compressibility of expanded polystyrene under load. Under the pressure equivalent to $4 \mathrm{~m}$ of sand, the height of the pelletized expanded polystyrene specimen decreased by a factor of 7.5, and its water permeability decreased by a factor of 300 . The water permeability of extruded polystyrene foam backfilling decreased by a factor of 2.4 at the pressure of $72 \mathrm{kPa}$ and the relative deformation of 0.39 . Testing has shown that extruded polystyrene foam is less compressible under load, which enables its use at a greater drain burial depth.

Multiple experiments have proved that clogging particles in water cause reduction in water permeability of geotextile filters wrapped around drain pipes [11-13]. Clogging survey of drain pipe geotextile filter was carried out using a setup shown in Figure 6. 

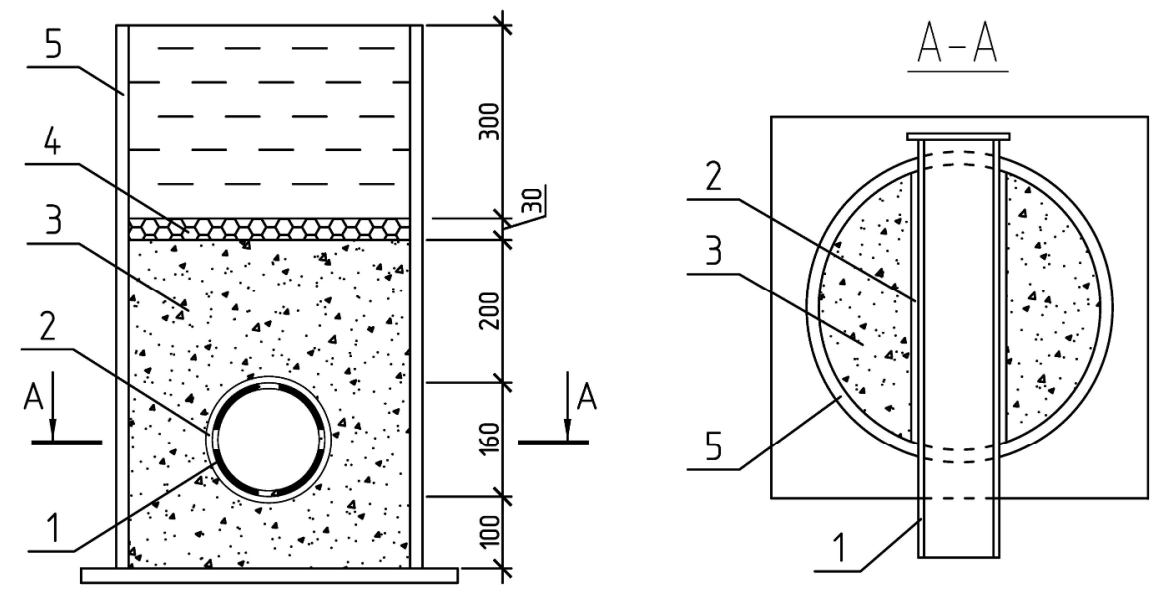

Fig. 6. Setup for drain wrapping survey. 1 - drain pipe, 2 - geotextile filter, 3 - sand filling, 4 gravel, 5 - box $Ø 500 \mathrm{~mm}$

A corrugated drain pipe $138 \mathrm{~mm}$ in diameter wrapped in geotextile with the density of 100 $\mathrm{g} / \mathrm{m}^{2}$ was placed in a box backfilled with medium-grained sand. The content of clayey particles in the filtering suspension was $0.8 \mathrm{~g} / \mathrm{l}$. Clayey particles were obtained by crushing clay loam. The total volume of water filtered was $2 \mathrm{~m}^{3}$. The curve of changing water inflow into the drain is shown in Figure 6.

Figure 7 clearly shows that the inflow of suspension into the drain is reduced by a factor of 14.8 towards the end of the experiment. Lower inflow into the drain is caused by clogging of the pores of the sand fill and the geotextile filter with silty-clayey particles contained in the suspension. Water permeability of the geotextile filter was determined with the help of a filtration tube both for the initial specimen and for the clogged specimen. Water permeability of the clogged geotextile filter reduced by a factor of 7.6, and its weight increased 1.7 times. This means that wrapping drain pipes in geotextile is not practicable if filtered water contains silty-clayey particles.

Typical drains are characterized by high material consumption and cost. The do not always guarantee normal conditions in underground rooms of buildings after commissioning. It is possible to reduce the cost of drainage system installation by using stone-free drains (Figure 8). The drains are installed over the cast-in-place cap of a singlerow pile foundation. The drains can be attached with wires to the eyes embedded into the cap. Small weight, low material consumption and quick installation are the main advantages of this design. It is necessary to use pipes and filling of stiff materials to prevent deformation of the drainage system structural members. If the filtered water contains clogging particles, the support structures can be designed with reinforced concrete caps and beams (Figure 9). The beams shall be installed with a gap to prevent particle accumulation in the drain aggregate. 


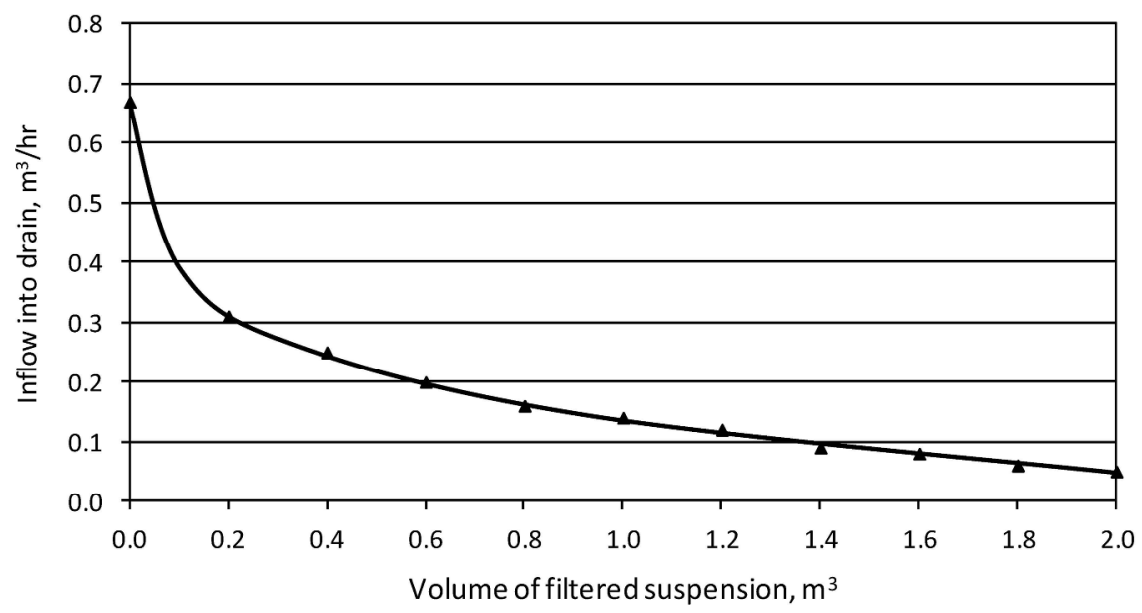

Fig. 7. Change of water inflow into the drain with sand filling
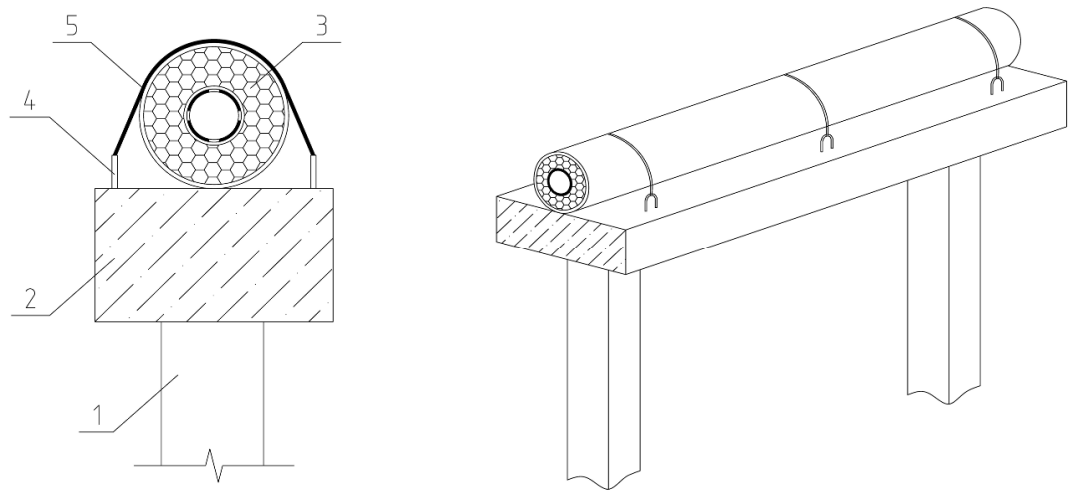

Fig. 8. Stone-free drain design in peaty soils without clogging particles in filtered water. $1-$ reinforced concrete pile, 2 - reinforced concrete cap, 3 - stone-free drainage, 4 - eye, 5 - wire
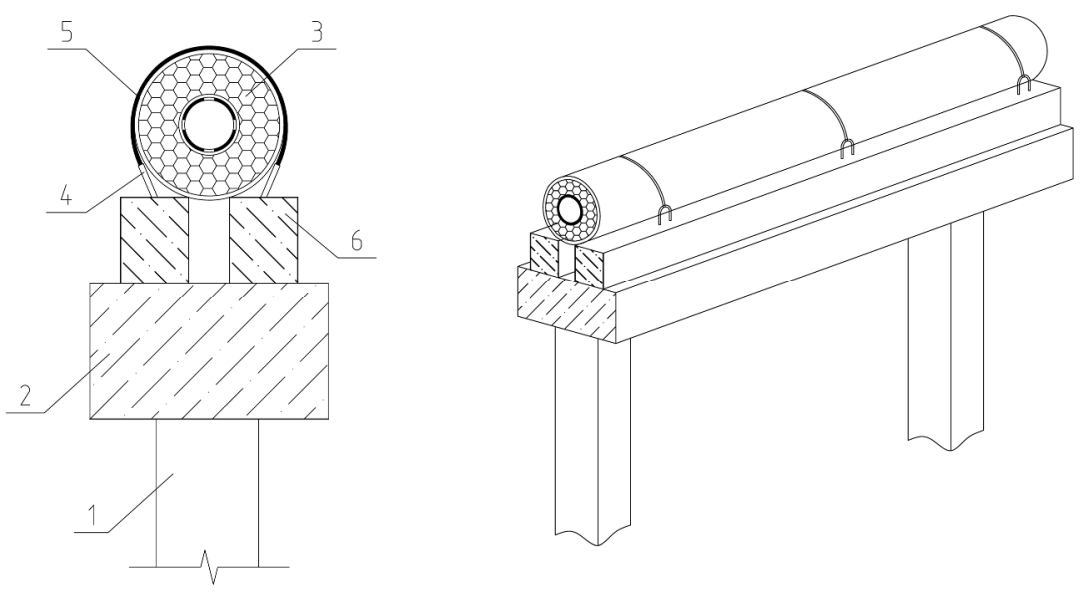

Fig. 9. Stone-free drain design in peaty soils with clogging particles: 1 - reinforced concrete pile, 2 reinforced concrete cap, 3 - stone-free drainage, 4 - eye, 5 - wire, 6 - reinforced concrete beam 


\section{Conclusions}

1. The use of advanced materials allows improving the cost efficiency and reducing the labour input of drain construction in peaty soils.

2. To prevent extensive deformation, the burial depth of a typical stone-free drainage system shall be limited by $2.5 \mathrm{~m}$.

3. Installation of stone-free drainage systems at greater depths requires using drain pipes and aggregate of non-yielding (stiff) materials.

\section{References}

1. Y.J. Han, H. K. Seong, and I. C. Youn, Yeong, Polymer Testing, 23, 239-244 (2004). DOI: $10.1016 / \mathrm{S} 0142-9418(03) 00100-4$.

2. M. Vandenbossche, M. Jimenez, M. Casetta, Reactive and functional polymers, 1(73), 53-59 (2013). DOI: 10.1016/j.reactfunctpolym.2012.09.002.

3. H.Y. Jeon, Polimer testing, 2(25), 176-180 (2006). DOI: 10.1016/j.polymertesting.2005.11.003.

4. S.A. Ariadurai, P. Potluri, I.L. Whyte, Textile research journal, 5, 345-351 (1999). DOI: $10.1177 / 004051759906900507$.

5. A. Bouazza, M. Freund, H. Nahlawi, Polymer Testing. 25(8), 1038-1043 (2016). DOI: 10.1016/j.polymertesting.2006.07.002.

6. R. Singh, S. Lavrykov, B.V. Ramarao, Colloids Surf A: Physicochem engineering aspects, 1(333), 96-107 (2009). DOI: 10.1016/j.colsurfa.2008.09.035.

7. B.J. Mullins; Roger D. Braddock; I.E. Agranovski, Journal of colloid and interface science, 1(279), 213-227 (2004). DOI: 10.1016/j.jcis.2004.06.064.

8. O. Zaborskaya, A. Nikitin, A. Nevzorov, Matec web of Conf., 106 (2017). DOI: 10.1051/matecconf/201710607013.

9. L.G.C.S. Correia, M. Ehrlich, M.B. Mendonca, Geotextiles and Geomembranes. 45, 17 (2017). DOI: 10.1016/j.geotexmem.2016.08.001.

10. V. Guillaume, S. Guillaume, M. Patrice, F. Yves-Henri, T. Nathalie, Geotextiles and Geomembranes, 44, 515-533 (2016). DOI: 10.1016/j.geotexmem.2016.02.002.

11. H. Y. Jeon, S H Kim, Y I Chung, H K Yoo and J Mlynarek, Polymer Testing, 22, 779784 (2003). DOI: 10.1016/S0142-9418(03)00012-6.

12. R.M. Koerner, G.R. Koerner, Geotextiles and Geomembranes, 43, 272-281 (2015). DOI: $10.1016 /$ j.geotexmem.2015.01.004.

13. L.A. Sañudo-Fontaneda, S.J. Coupe, S.M. Charlesworthb, E.G. Rowlands, Geotextiles and Geomembranes, 46, 559-565 (2018). DOI: 10.1016/j.geotexmem.2018.04.006. 